\section{J'TI}

JOURNAL OF

TRAUMA AND INJURY

\title{
Initial Experiences of Extracorporeal Membrane Oxygenation for Trauma Patients at a Single Regional Trauma Center in South Korea
}

Received: November 24, 2020

Revised: December 4, 2020

Accepted: December 17, 2020

\section{Correspondence to}

Pil Young Jung, M.D., Ph.D.

Department of Surgery, Yonsei University Wonju College of Medicine, 20 Ilsan-ro,

Wonju 26426, Korea

Tel: + 82-33-741-0573

Fax: +82-33-741-0574

E-mail: surgery4trauma@yonsei.ac.kr ORCID: https://orcid.org/0000-00016460-8072
Ji Wool Ko, M.D. ${ }^{1,2}$, Il Hwan Park, M.D., Ph.D. ${ }^{3}$, Chun Sung Byun, M.D., Ph.D. ${ }^{3}$, Sung Woo Jang, M.D. ${ }^{1,2}$, Pil Young Jung, M.D., Ph.D. ${ }^{1,2}$

${ }^{1}$ Department of Surgery, Yonsei University Wonju College of Medicine, Wonju, Korea

${ }^{2}$ Regional Trauma Center, Wonju Severance Christian Hospital, Wonju, Korea

${ }^{3}$ Department of Thoracic Surgery, Yonsei University Wonju College of Medicine, Wonju, Korea

Purpose: For severe lung injuries or acute respiratory distress syndrome that occurs during critical care due to trauma, extracorporeal membrane oxygenation (ECMO) may be used as a salvage treatment. This study aimed to describe the experiences at a single center with the use of ECMO in trauma patients.

Methods: We enrolled a total of 25 trauma patients who were treated with ECMO between January 2015 and December 2019 at a regional trauma center. We analyzed and compared patients' characteristics between survivors and non-survivors through a medical chart review. We also compared the characteristics of patients between direct and indirect lung injury groups.

Results: The mean age of the 25 patients was $45.9 \pm 19.5$ years, and 19 patients $(76.0 \%)$ were male. The mean Injury Severity Score was $26.1 \pm 10.1$. Ten patients $(40.0 \%)$ had an Abbreviated Injury Scale (AIS) 3 score of 4, and six patients (24.0\%) had an AIS 3 score of 5 . There were 19 cases $(76.6 \%)$ of direct lung injury. The mortality rate was $60.0 \%$ $(n=15)$. Sixteen patients $(64.0 \%)$ received a loading dose of heparin for the initiation of ECMO. There was no significant difference in heparin use between the survivors and non-survivors (70\% in survivors vs. $60 \%$ in non-survivors, $p=0.691)$. When comparing the direct and indirect lung injury groups, there were no significant differences in variables other than age and ECMO onset time.

Conclusions: If more evidence is gathered, risk factors and indications will be identified and we expect that more trauma patients will receive appropriate treatment with ECMO.

Keywords: Extracorporeal membrane oxygenation; Multiple trauma 


\section{INTRODUCTION}

There are two main causes of acute respiratory distress syndrome (ARDS) in trauma patients. The first is direct severe lung injury, which progresses to respiratory failure [1]. The second occurs among patients who receive critical care due to multiple traumatic injuries [2]. Despite management in the intensive care unit (ICU), severe lung injury with ARDS or cardiopulmonary insufficiency is still associated with high morbidity and mortality $[3,4]$. Extracorporeal membrane oxygenation (ECMO) has been used in patients who have undergone pulmonary transplantation and require additional cardiopulmonary support when the standard means of ventilation are ineffective [5]. Thus, ECMO might be used as a temporary replacement for the damaged lung to provide sufficient ventilation and oxygenation, to improve hypercapnia, and to allow time for recovery of the lung $[6,7]$. However, due to the possibility of bleeding complications, the use of ECMO at trauma care centers has been limited $[8,9]$. Inadequate research has been conducted on the use of ECMO in trauma patients. South Korea has 17 trauma centers; however, ECMO is rarely used in the management of trauma.

This study retrospectively analyzed the characteristics of trauma patients in whom ECMO was used. Data were obtained from the Korea Trauma Data Bank (KTDB), which was established in 2014. This study aimed to describe the experiences at a single institution with the use of ECMO in trauma patients.

\section{METHODS}

\section{Patient selection and data collection}

Trauma patients who underwent ECMO at a single regional trauma center from January 2015 to December 2019 were enrolled. The charts prospectively stored in the KTDB were analyzed retrospectively. Of the 27 patients, two were excluded. These two patients experienced brain death due to trauma and required ECMO maintenance as organ donors (Fig. 1). Patient characteristics, including age, sex, type of injury (traffic accident, crush injury, hanging, fall, drowning, electrical injury, blunt injury), Glasgow Coma Scale (GCS), systolic blood pressure (SBP) on arrival at the emergency department (ED), and whether cardiopulmonary resuscitation was performed in the ED were confirmed. With a description of the damage, including the Injury Severity Score (ISS), the degree of lung injury (represented by the Abbreviated Injury Scale [AIS] 3 ), and whether the lung injury was direct (defined as AIS 3 score of 4 or 5), the need for surgical intervention was evaluated. The amount of transfusion agents administered (red blood cells, fresh frozen plasma, and platelets) during 24 hours after arrival at the hospital and the total amount of transfusion during hospitalization were recorded. The clinical outcomes included the duration of hospital stay, continuous renal replacement therapy (CRRT), and mortality.

The average time from admission to the initiation of ECMO and the duration for which ECMO waw provided, the mode of ECMO (veno-venous [VV], veno-arterial [VA], and multiple), the catheter approach used, and administration of heparin were analyzed. The partial pressure of arterial oxygen $\left(\mathrm{PaO}_{2}\right)$ and partial pressure of carbon dioxide $\left(\mathrm{PaCO}_{2}\right)$ were assessed before and after ECMO. In addition, the values of hemoglobin $(\mathrm{Hgb})$ and lactate were evaluated. The pre-ECMO values were defined as the last values checked before ECMO application, and the post-ECMO values were checked within $30 \mathrm{~min}$ utes to an hour after ECMO application.

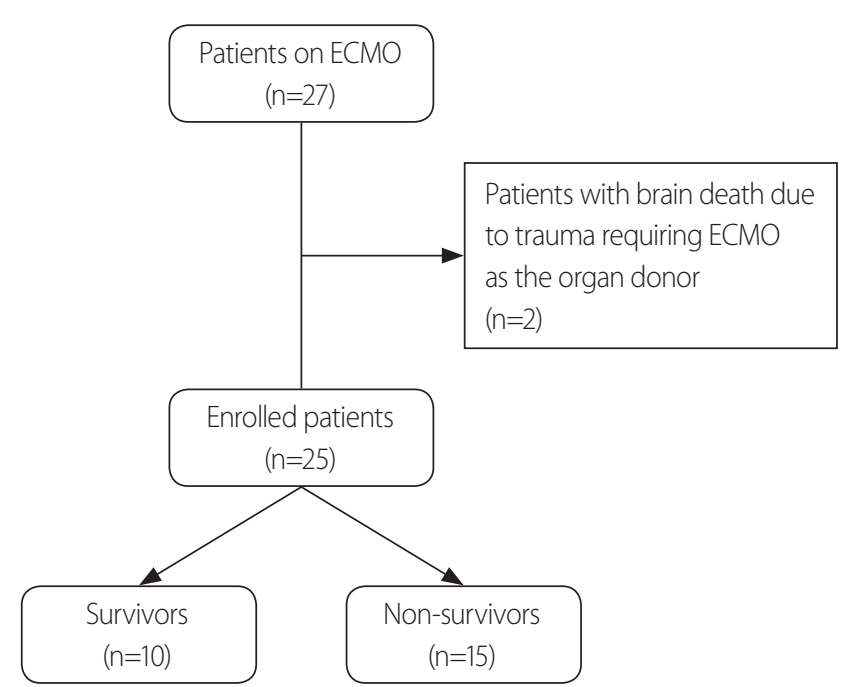

Fig. 1. Flow chart of the study design. ECMO: extracorporeal membrane oxygenation. 


\section{Techniques of ECMO}

The criteria for application of ECMO were hypoxemia $\left(\mathrm{PaO}_{2} /\right.$ fraction of inspired oxygen $\left[\mathrm{FiO}_{2}\right]<200 \mathrm{mmHg}$, $\mathrm{FiO}_{2}$ 0.8-1.0) during a ventilation time longer than 8 hours; tidal volume $>4-6 \mathrm{~mL} / \mathrm{kg}$ ideal body weight; inspiratory pressure $>32-34 \mathrm{mmHg}$; respiratory acidosis ( $\mathrm{pH}<7.25$ ), and/or arterial oxygen saturation $<90 \%$ [10]. If the above criteria were met, the thoracic surgeon inserted the catheters and primed the machine before initiating ECMO. The ECMO machine used in this study requires priming before use (QUDROX PLS, Maquet, Rastatt, Germany). The Seldinger method was mainly used for catheter insertion. ECMO was regulated and removed while clinical biomarkers of oxygenation were confirmed by a thoracic surgeon.

\section{Statistical analysis}

The statistical analysis was performed using SPSS version 25.0 (IBM Corp., Armonk, NY, USA). Continuous variables are expressed as mean \pm standard deviation. Categorical variables are expressed as absolute numbers and percentages. Comparisons between groups were performed using the chi-square test or Fisher exact test for categorical values and the Student $t$-test or the Mann-Whitney $U$-test for continuous values. A $p$-value of less than 0.05 was considered to indicate statistical significance.

\section{RESULTS}

\section{Patient data}

The mean age of the 25 patients was $45.9 \pm 19.5$ years, and 19 patients $(76.0 \%)$ were male. The most common cause of injury was traffic accidents, followed by falls, and 19 patients $(76.0 \%)$ had direct lung injuries. The mean GCS score was $6.8 \pm 5.3$. The SBP of seven patients $(28.0 \%)$ was not confirmed on arrival at the ED and the SBP of seven patients $(28.0 \%)$ was less than $90 \mathrm{mmHg}$. The mean ISS was $26.1 \pm 10.1$. Ten patients (40.0\%) had an AIS 3 score of 4 and six patients (24.0\%) had an AIS 3 score of 5 points. Ten patients (40.0\%) underwent surgery and 11 (44.0\%) underwent CRRT. The mean hospital stay was $26.1 \pm 39.9$ days and the average amount of total blood transfused during hospitalization was $50.0 \pm 76.6$. The mortality rate was $60.0 \%(n=15)$ (Table 1$)$.

Table 1. Patient characteristics

\begin{tabular}{|c|c|}
\hline Variable & Value $(n=25)$ \\
\hline Age (years) & $45.9 \pm 19.5$ \\
\hline Sex (male) & $19(76.0)$ \\
\hline \multicolumn{2}{|l|}{ Type of injury } \\
\hline Traffic accident & $8(32.0)$ \\
\hline Crush injury & $1(4.0)$ \\
\hline Hanging & $1(4.0)$ \\
\hline Fall & $7(28.0)$ \\
\hline Drowning & $6(24.0)$ \\
\hline Electrical injury & $1(4.0)$ \\
\hline Blunt injury & $1(4.0)$ \\
\hline GCS & $6.8 \pm 5.3$ \\
\hline \multicolumn{2}{|l|}{ SBP } \\
\hline Unchecked & $7(28.0)$ \\
\hline$\geq 90 \mathrm{mmHg}$ & $11(44.0)$ \\
\hline$<90 \mathrm{mmHg}$ & $7(28.0)$ \\
\hline CPR & $12(48.0)$ \\
\hline ISS & $26.1 \pm 10.1$ \\
\hline \multicolumn{2}{|l|}{ AIS 3} \\
\hline o Score & $5(20.2)$ \\
\hline 1 Score & $0(0.0)$ \\
\hline 2 Score & $1(4.0)$ \\
\hline 3 Score & $3(12.0)$ \\
\hline 4 Score & $10(40.0)$ \\
\hline 5 Score & $6(24.0)$ \\
\hline Direct lung injury & $19(76.0)$ \\
\hline Surgery performed & $10(40.0)$ \\
\hline RBCs in 24 hours & $10.6 \pm 14.5$ \\
\hline FFP in 24 hours & $8.7 \pm 12.8$ \\
\hline Platelets in 24 hours & $2.2 \pm 5.9$ \\
\hline Total transfusion during hospitalization & $50.0 \pm 76.6$ \\
\hline Hospital stay (days) & $26.1 \pm 39.9$ \\
\hline Concurrent CRRT & $11(44.0)$ \\
\hline Mortality & $15(60.0)$ \\
\hline
\end{tabular}

Values are presented as mean \pm standard deviation or number (\%). GCS: Glasgow Coma Scale, SBP: systolic blood pressure, CPR: cardiopulmonary resuscitation, ISS: Injury Severity Score, AIS: Abbreviated Injury Scale, RBCs: red blood cells, FFP: fresh frozen plasma, CRRT: continuous renal replacement therapy. 


\section{ECMO-related factors}

ECMO initiation required a mean duration of $58.0 \pm 135.4$ hours. The mean duration of ECMO maintenance was $90.9 \pm 123.9$ hours. VV-ECMO was used in 13 patients (52.0\%), and six catheter insertion sites were in the femoral veins and seven in the femoral and jugular veins. VA-ECMO was used in 10 patients (40.0\%), and the femoral vein and artery were used. In the other two cases, VV-ECMO was applied after VA-ECMO in one case, and VV-ECMO was applied after VV arterial ECMO in the other case. The jugular vein and femoral artery were accessed, and the femoral artery was replaced with the femoral vein. Six-

\section{Table 2. ECMO-related factors}

\begin{tabular}{|c|c|}
\hline Factor & Value $(n=25)$ \\
\hline Start of ECMO (hours) & $58.0 \pm 135.4$ \\
\hline Duration of ECMO (hours) & $90.9 \pm 123.9$ \\
\hline \multicolumn{2}{|l|}{ Mode of ECMO } \\
\hline VV & $13(52.0)$ \\
\hline VA & $10(40.0)$ \\
\hline Multiple & $2(8.0)$ \\
\hline \multicolumn{2}{|l|}{ Catheter access } \\
\hline Femoral vein, femoral vein & $6(24.0)$ \\
\hline Femoral vein, jugular vein & $7(28.0)$ \\
\hline Femoral vein, femoral artery & $10(40.0)$ \\
\hline Jugular vein, femoral artery $\rightarrow$ vein & $2(8.0)$ \\
\hline Heparin & $16(64.0)$ \\
\hline Pre-ECMO ${ }^{\mathrm{a}} \mathrm{PaO}_{2}(\mathrm{mmHg})$ & $56.0 \pm 12.7$ \\
\hline Pre-ECMO ${ }^{\mathrm{PaCO}}(\mathrm{mmHg})$ & $63.4 \pm 23.3$ \\
\hline Pre-ECMO ${ }^{\mathrm{a}} \mathrm{Hgb}(\mathrm{g} / \mathrm{dL})$ & $11.4 \pm 2.3$ \\
\hline Pre-ECMO ${ }^{\mathrm{a}}$ lactate (mmol/L) & $6.1 \pm 4.3$ \\
\hline Post-ECMO ${ }^{b} \mathrm{PaO}_{2}(\mathrm{mmHg})$ & $148.1 \pm 108.5$ \\
\hline Post-ECMO ${ }^{\mathrm{b}} \mathrm{PaCO}_{2}(\mathrm{mmHg})$ & $39.1 \pm 18.0$ \\
\hline Post-ECMO ${ }^{b} \mathrm{Hgb}(\mathrm{g} / \mathrm{dL})$ & $11.1 \pm 1.9$ \\
\hline Post-ECMO ${ }^{b}$ lactate $(\mathrm{mmol} / \mathrm{L})$ & $7.3 \pm 3.6$ \\
\hline
\end{tabular}

Values are presented as mean \pm standard deviation or number (\%).

ECMO: extracorporeal membrane oxygenation, VV: veno-venous, VA: venoartriol, $\mathrm{PaO}_{2}$ : partial pressure of arterial oxygen, $\mathrm{PaCO}_{2}$ : partial pressure of carbon dioxide, Hgb: hemoglobin.

${ }^{\text {a }}$ Pre-ECMO values were defined as the last checked values before ECMO application.

${ }^{\mathrm{b}}$ Post-ECMO values were checked within 30 minutes to an hour after ECMO application. teen patients $(64.0 \%)$ were administered a loading dose of heparin for initiation of ECMO. The mean pre-ECMO $\mathrm{PaO}_{2}$ was $56.0 \pm 12.7 \mathrm{mmHg}$, and pre-ECMO $\mathrm{PaCO}_{2}$ was $63.4 \pm 23.3 \mathrm{mmHg}$. The mean pre-ECMO Hgb level was $11.4 \pm 2.3 \mathrm{~g} / \mathrm{dL}$, and pre-ECMO lactate was $6.1 \pm 4.3 \mathrm{mmol} / \mathrm{L}$. The mean post-ECMO $\mathrm{PaO}_{2}$ was $148.1 \pm 108.5 \mathrm{mmHg}$, and post-ECMO $\mathrm{PaCO}_{2}$ was $39.1 \pm 18.0 \mathrm{mmHg}$. The mean post-ECMO Hgb level was $11.1 \pm 1.9 \mathrm{~g} / \mathrm{dL}$, and post-ECMO lactate was $7.3 \pm 3.6 \mathrm{mmol} / \mathrm{L}$ (Table 2).

\section{Comparison between survivors and non-survivors}

Non-survivors more frequently received CRRT than survivors; however, this difference was not meaningful $(20 \%$ in survivors vs. $60 \%$ in non-survivors, $p=0.099$ ) (Table 3 ). There was also no significant difference in the use of heparin between survivors and non-survivors (70\% in survi-

Table 3. Comparison of characteristics between survivors and non-survivors

\begin{tabular}{|lccc|}
\hline Characteristic & $\begin{array}{c}\text { Survivors } \\
(\mathbf{n}=10)\end{array}$ & $\begin{array}{c}\text { Non-survi- } \\
\text { vors }(\mathbf{n}=15)\end{array}$ & $\boldsymbol{p}$-value \\
\hline Age (years) & $41.0 \pm 16.7$ & $49.1 \pm 21.1$ & 0.318 \\
\hline Sex (male) & $7(70.0)$ & $12(80.0)$ & 0.653 \\
GCS & $7.1 \pm 5.6$ & $6.5 \pm 5.3$ & 0.799 \\
SBP & & & $0.088^{\mathrm{a}}$ \\
Unchecked & $2(20.0)$ & $5(33.3)$ & \\
$\geq 90$ mmHg & $7(70.0)$ & $4(26.7)$ & \\
$<90$ mmHg & $1(10.0)$ & $6(40.0)$ & \\
CPR & $4(40.0)$ & $8(53.4)$ & 0.688 \\
ISS & $25.9 \pm 10.4$ & $26.3 \pm 10.3$ & 0.932 \\
Surgery performed & $4(40.0)$ & $6(40.0)$ & $>0.999$ \\
RBCs in 24 hours & $6.8 \pm 8.4$ & $13.2 \pm 17.2$ & 0.288 \\
FFP in 24 hours & $5.1 \pm 7.3$ & $11.1 \pm 15.2$ & 0.257 \\
Platelets in 24 hours & $0.0 \pm 0.0$ & $3.7 \pm 7.3$ & 0.123 \\
Total transfusion during & $32.6 \pm 31.3$ & $61.7 \pm 95.3$ & 0.364 \\
hospitalization & & & \\
\hline CRRT & $2(20.0)$ & $9(60.0)$ & 0.099 \\
Hospital day (days) & $53.2 \pm 52.6$ & $8.2 \pm 9.3$ & 0.003 \\
\hline
\end{tabular}

Values are presented as mean \pm standard deviation or number (\%). GCS: Glasgow Coma Scale, SBP: systolic blood pressure, CPR: cardiopulmonary resuscitation, ISS: Injury Severity Score, RBCs: red blood cells, FFP: fresh frozen plasma, CRRT: continuous renal replacement therapy.

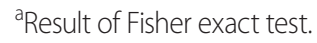


Table 4. Survivors versus non-survivors according to ECMO-related factors

\begin{tabular}{|c|c|c|c|}
\hline Factor & Survivors $(n=10)$ & Non-survivors $(n=15)$ & $p$-value \\
\hline Start of ECMO (hours) & $61.1 \pm 171.5$ & $55.9 \pm 111.7$ & 0.920 \\
\hline Duration of ECMO (hours) & $65.1 \pm 32.4$ & $108.1 \pm 157.6$ & 0.406 \\
\hline Mode of ECMO & & & $0.109^{c}$ \\
\hline VV & $6(60.0)$ & $7(46.7)$ & \\
\hline VA & $4(40.0)$ & $6(40.0)$ & \\
\hline Multiple & $0(0.0)$ & $2(13.3)$ & \\
\hline Heparin & $7(70.0)$ & $9(60.0)$ & 0.691 \\
\hline Pre-ECMO $\mathrm{PaO}_{2}(\mathrm{mmHg})$ & $57.1 \pm 14.5$ & $55.2 \pm 11.9$ & 0.720 \\
\hline Pre-ECMO $\mathrm{PaCO}_{2}(\mathrm{mmHg})$ & $59.4 \pm 17.5$ & $66.0 \pm 26.7$ & 0.495 \\
\hline Pre-ECMO $\mathrm{Hgb}(\mathrm{g} / \mathrm{dL})$ & $11.4 \pm 2.6$ & $11.4 \pm 2.1$ & 0.978 \\
\hline Pre-ECMO lactate $(\mathrm{mmol} / \mathrm{L})$ & $4.5 \pm 2.5$ & $7.2 \pm 5.0$ & 0.123 \\
\hline Post-ECMO ${ }^{\mathrm{b}} \mathrm{PaO}_{2}(\mathrm{mmHg})$ & $176.2 \pm 138.7$ & $129.5 \pm 82.9$ & 0.302 \\
\hline Post-ECMO ${ }^{b} \mathrm{PaCO}_{2}(\mathrm{mmHg})$ & $39.8 \pm 21.9$ & $38.6 \pm 15.7$ & 0.881 \\
\hline Post-ECMO ${ }^{b} \mathrm{Hgb}(\mathrm{g} / \mathrm{dL})$ & $11.1 \pm 1.8$ & $11.1 \pm 2.0$ & 0.997 \\
\hline Post-ECMO ${ }^{b}$ lactate $(\mathrm{mmol} / \mathrm{L})$ & $6.3 \pm 2.2$ & $8.1 \pm 4.3$ & 0.255 \\
\hline
\end{tabular}

Values are presented as mean \pm standard deviation or number (\%).

ECMO: extracorporeal membrane oxygenation, $\mathrm{VV}$ : veno-venous, VA: venoartriol, $\mathrm{PaO}_{2}$ : partial pressure of arterial oxygen, PaCO${ }_{2}$ : partial pressure of carbon dioxide, Hgb: hemoglobin.

aPre-ECMO values were defined as the last checked values before ECMO application.

bost-ECMO values were checked within 30 minutes to an hour after ECMO application.

${ }^{\mathrm{c}}$ Result of Fisher exact test.

vors vs. $60 \%$ in non-survivors, $p=0.691$ ) (Table 4 ).

\section{Comparison between the direct lung injury group and indirect lung injury group}

The patients in the direct injury group were significantly younger than those in the indirect injury group (39.9 \pm 17.5 years vs. $56.4 \pm 19.4$ years, $p=0.040)$. The ECMO start time was faster in the direct injury group $(10.5 \pm 25.2$ hours vs. $142.4 \pm 203.1$ hours, $p=0.016)$. However, there was no significant difference in mortality between the direct and indirect lung injury groups ( $56.3 \%$ vs. $66.7 \%, p=0.691$ ) (Table 5).

\section{DISCUSSION}

In cases where ECMO is used in trauma patients, the causes of severe lung injury include insufficient ventilator care during conservative treatment or ARDS during ICU care for multiple traumas [1]. ECMO is sometimes selected as a salvage technique in trauma; however, its use is still controversial [11]. In South Korea, it is considered as an alternative treatment; hence, it is rarely used. Since it is challenging to find data on the use of ECMO in trauma, we analyzed its use in trauma cases.

In total, 25 patients were analyzed, including those who had sustained trauma due to drowning and hanging. Drowning was considered as a direct lung injury, and was included in the group of patients with an AIS 3 score of 5. In the case of hanging, ECMO was applied since ARDS occurred during ICU care for a patient with an AIS 1 score of 5. In this study, VA-ECMO was most frequently applied in patients with injuries caused by hanging and drowning.

There were nine patients in whom heparin was not administered during ECMO application (three survivors [30.0\%] and six non-survivors [40.0\%]). In patients with multiple traumas, the chances of bleeding are high, mak- 
Table 5. Comparison of characteristics between patients with direct and indirect lung injuries

\begin{tabular}{|c|c|c|c|}
\hline Characteristics & Direct injury $(n=16)$ & Indirect injury ( $n=9$ ) & $p$-value \\
\hline Age (years) & $39.9 \pm 17.5$ & $56.4 \pm 19.4$ & 0.040 \\
\hline Sex (male) & $11(68.8)$ & 8 (88.9) & 0.364 \\
\hline GCS & $9.0 \pm 5.6$ & $5.5 \pm 4.8$ & 0.114 \\
\hline SBP & & & $0.472^{c}$ \\
\hline Unchecked & $4(25.0)$ & $3(33.3)$ & \\
\hline$\geq 90 \mathrm{mmHg}$ & $8(50.0)$ & $3(33.3)$ & \\
\hline$<90 \mathrm{mmHg}$ & $4(25.0)$ & $3(33.3)$ & \\
\hline CPR & $9(56.3)$ & $3(33.3)$ & 0.411 \\
\hline ISS & $26.8 \pm 12.2$ & $25.0 \pm 5.4$ & 0.688 \\
\hline Surgery performed & $5(31.3)$ & $5(55.6)$ & 0.397 \\
\hline Start of ECMO (hours) & $10.5 \pm 25.2$ & $142.4 \pm 203.1$ & 0.016 \\
\hline Duration of ECMO (hours) & $102.9 \pm 146.4$ & $69.7 \pm 71.0$ & 0.531 \\
\hline Heparin & $11(68.8)$ & $5(55.6)$ & 0.671 \\
\hline Pre-ECMO $\mathrm{PaO}_{2}(\mathrm{mmHg})$ & $58.9 \pm 12.7$ & $50.7 \pm 11.6$ & 0.125 \\
\hline Pre-ECMO $\mathrm{PaCO}_{2}(\mathrm{mmHg})$ & $63.8 \pm 28.1$ & $62.6 \pm 12.2$ & 0.906 \\
\hline Pre-ECMO $\mathrm{Hgb}(\mathrm{g} / \mathrm{dL})$ & $11.5 \pm 2.7$ & $11.2 \pm 1.4$ & 0.769 \\
\hline Pre-ECMO lactate (mmol/L) & $6.4 \pm 4.4$ & $5.5 \pm 1.4$ & 0.633 \\
\hline Post-ECMO ${ }^{b} \mathrm{PaO}_{2}(\mathrm{mmHg})$ & $152.5 \pm 118.3$ & $140.4 \pm 94.5$ & 0.796 \\
\hline Post-ECMO ${ }^{b} \mathrm{PaCO}_{2}(\mathrm{mmHg})$ & $41.7 \pm 21.2$ & $34.4 \pm 9.2$ & 0.337 \\
\hline Post-ECMO ${ }^{b} \mathrm{Hgb}(\mathrm{g} / \mathrm{dL})$ & $11.1 \pm 2.0$ & $11.1 \pm 1.7$ & 0.940 \\
\hline Post-ECMO ${ }^{b}$ lactate $(\mathrm{mmol} / \mathrm{L})$ & $7.8 \pm 3.6$ & $6.5 \pm 3.6$ & 0.389 \\
\hline CRRT & $7(43.8)$ & $4(44.4)$ & $>0.999$ \\
\hline Hospital stay (days) & $29.8 \pm 48.2$ & $19.8 \pm 18.7$ & 0.558 \\
\hline Mortality & $9(56.3)$ & $6(66.7)$ & 0.691 \\
\hline
\end{tabular}

Values are presented as mean \pm standard deviation or number (\%).

GCS: Glasgow Coma Scale, SBP: systolic blood pressure, CPR: cardiopulmonary resuscitation, ISS: Injury Severity Score, ECMO: extracorporeal membrane oxygenation, $\mathrm{PaO}_{2}$ : partial pressure of arterial oxygen, $\mathrm{PaCO}_{2}$ : partial pressure of carbon dioxide, Hgb: hemoglobin, CRRT: continuous renal replacement therapy.

aPre-ECMO values were defined as the last checked values before ECMO application.

${ }^{b}$ Post-ECMO values were checked within 30 minutes to an hour after ECMO application.

${ }^{\mathrm{c}}$ Result of Fisher exact test.

ing it challenging to use anti-hemostatic agents [12-14]. Recent studies have shown that ECMO without the use of heparin has good outcomes if VV-ECMO is applied in cases of trauma with a high risk of bleeding $[11,12,15]$. Although our study did not compare the group to one in which only VV-ECMO was applied, the administration or non-administration of heparin did not affect survival.

Kidney injury might occur due to complications during ECMO application. Acute kidney injury (AKI) during
ECMO is caused by hypoperfusion, loss of autoregulation, hypoxia, nephrotoxic drugs, and systemic inflammation [16]. Other reasons for which CRRT might be required include acid-base and electrolyte disturbances and fluid overload [16]. Hamdi and Palmer [16] reported an AKI incidence of more than $80 \%$ with $50 \%$ of those patients requiring renal replacement therapy within the first week of ECMO application. Thongprayoon et al. [17] reported that the mortality in patients who received CRRT was 
3.7-fold higher due to AKI progression during ECMO application. In our study, 11 patients (44.0\%) with AKI were treated with CRRT, and there was no significant difference in the need for CRRT between survivors and non-survivors; however, CRRT was provided more frequently in non-survivors.

In our study, two cases of indirect lung injury were due to a cervical spine injury; one case was due to electric shock, and one case was due to bowel injury. Five patients had long bone or pelvic bone fractures, and two patients had liver injuries. The reasons for using ECMO were ARDS (four cases), pulmonary thromboembolism occurrence (two cases), post-cardiac arrest (one case), aspiration pneumonia (one case), and asphyxia (one case). Engström et al. [18] reported that the incidence of respiratory failure was high in ICU-treated patients with pelvic fractures, and the risk factors were the degree of lung contusion and surgery. There were few patients in our study in whom we could not analyze the risk factors that could cause ARDS due to pelvic bone fractures. However, these patients comprised the majority of the indirect lung injury group.

There were significant differences in age and ECMO onset time between the direct and indirect lung injury groups. As for the age difference, since the population was small, it would be inappropriate to conclude that those with a younger age suffered more direct injuries based on these results alone. In cases of direct lung injury, the decision to apply ECMO would have been made more quickly because oxygenation after the injury was unfavorable due to severe lung contusions. In cases of indirect lung injury, the start time of ECMO might have been delayed because ARDS occurred due to complications during ICU care.

The other variables showed no significant differences between the two groups. None of the patients had previous lung disease. In the patients with indirect lung injuries, lung disease occurred acutely, similarly to lung injuries due to trauma, and ECMO was applied in such patients. Compared with traumatic direct lung injuries requiring ECMO, performing ECMO in response to an acute disease pattern in trauma led to no significant differences, so it is worth considering ECMO more actively in patients with severe lung injuries.

The limitations of this study include the fact that it was a retrospective analysis comprising a few patients. Therefore, in this study, patients with hanging and drowning were included, and in these cases, VA-ECMO was applied. Another limitation of our study is that not only trauma patients were analyzed. In addition, serial checks of clinical biomarkers for ECMO monitoring have not been standardized. Furthermore, before ECMO application, ECMO-related factors (positive end expiratory pressure level or the peak flow ratio) could not be analyzed in the study because many values were missing from the medical charts. As a final limitation, there was one case of traumatic brain injury; however, the mean GCS was 6.8. The GCS was recorded in the nursing records upon arrival at the ED. Even a patient has not experienced a brain injury, if there is a loss of consciousness due to hypovolemic shock, the GCS may be evaluated as low. Thus, a limitation is that continuous evaluations of the GCS were required, but not conducted. ECMO has been applied at other South Korea trauma centers in few trauma patients. Therefore, a multicenter analysis is necessary, and we expect that more research will be conducted at other institutions in the future.

\section{CONCLUSION}

ECMO is a feasible treatment option when trauma patients have a severe chest injury or ARDS caused by other injuries. Since no significant difference was found in comparison to cases where ECMO was used in patients with acute respiratory disease, active use of ECMO is recommended in patients with direct lung injuries who meet the criteria for applying ECMO. If more research is conducted, risk factors and indications will be identified, and we expect that more trauma patients will receive appropriate treatment with ECMO.

\section{REFERENCES}

1. Michaels AJ. Management of post traumatic respiratory failure. Crit Care Clin 2004;20:83-99.

2. Michaels AJ, Schriener RJ, Kolla S, Awad SS, Rich PB, Reickert $\mathrm{C}$, et al. Extracorporeal life support in pulmonary failure after 
trauma. J Trauma 1999;46:638-45.

3. Chen CY, Hsu TY, Chen WK, Muo CH, Chen HC, Shih HM. The use of extracorporeal membrane oxygenation in trauma patients: a national case-control study. Medicine (Baltimore) 2018;97:e12223.

4. Probst C, Pape HC, Hildebrand F, Regel G, Mahlke L, Giannoudis $\mathrm{P}$, et al. 30 years of polytrauma care: an analysis of the change in strategies and results of 4849 cases treated at a single institution. Injury 2009;40:77-83.

5. Terragni P, Faggiano C, Ranieri VM. Extracorporeal membrane oxygenation in adult patients with acute respiratory distress syndrome. Curr Opin Crit Care 2014;20:86-91.

6. Keel M, Meier C. Chest injuries - what is new? Curr Opin Crit Care 2007;13:674-9.

7. Keel M, Trentz O. Pathophysiology of polytrauma. Injury 2005;36:691-709.

8. Brodie D, Bacchetta M. Extracorporeal membrane oxygenation for ARDS in adults. N Engl J Med 2011;365:1905-14.

9. Pfeifer R, Teuben M, Andruszkow H, Barkatali BM, Pape HC. Mortality patterns in patients with multiple trauma: a systematic review of autopsy studies. PLoS One 2016;11:e0148844.

10. Murray JF, Matthay MA, Luce JM, Flick MR. An expanded definition of the adult respiratory distress syndrome. Am Rev Respir Dis 1988;138:720-3.

11. Robba C, Ortu A, Bilotta F, Lombardo A, Sekhon MS, Gallo F, et al. Extracorporeal membrane oxygenation for adult respiratory distress syndrome in trauma patients: a case series and system- atic literature review. J Trauma Acute Care Surg 2017;82:165-73.

12. Kopp R, Bensberg R, Henzler D, Niewels A, Randerath S, Rossaint $\mathrm{R}$, et al. Hemocompatibility of a miniaturized extracorporeal membrane oxygenation and a pumpless interventional lung assist in experimental lung injury. Artif Organs 2010;34:13-21.

13. Arlt M, Philipp A, Voelkel S, Rupprecht L, Mueller T, Hilker M, et al. Extracorporeal membrane oxygenation in severe trauma patients with bleeding shock. Resuscitation 2010;81:804-9.

14. Wang C, Zhang L, Qin T, Xi Z, Sun L, Wu H, et al. Extracorporeal membrane oxygenation in trauma patients: a systematic review. World J Emerg Surg 2020;15:51.

15. Wen PH, Chan WH, Chen YC, Chen YL, Chan CP, Lin PY. Non-heparinized ECMO serves a rescue method in a multitrauma patient combining pulmonary contusion and nonoperative internal bleeding: a case report and literature review. World J Emerg Surg 2015;10:15.

16. Hamdi T, Palmer BF. Review of extracorporeal membrane oxygenation and dialysis-based liver support devices for the use of nephrologists. Am J Nephrol 2017;46:139-49.

17. Thongprayoon C, Kaewput W, Thamcharoen N, Bathini T, Watthanasuntorn $\mathrm{K}$, Lertjitbanjong $\mathrm{P}$, et al. Incidence and impact of acute kidney injury after liver transplantation: a meta-analysis. J Clin Med 2019;8:372.

18. Engström J, Reinius H, Ström J, Bergström MF, Larsson IM, Larsson A, et al. Lung complications are common in intensive care treated patients with pelvis fractures: a retrospective cohort study. Scand J Trauma Resusc Emerg Med 2016;24:52. 